\title{
Clinical implementation of whole-genome array CGH as a first-tier test in 5080 pre and postnatal cases
}

Sang-Jin Park ${ }^{1 \dagger}$, Eun Hye Jung ${ }^{1}$, Ran-Suk Ryu ${ }^{1}$, Hyun Woong Kang ${ }^{2}$, Jung-Min Ko ${ }^{3}$, Hyon J Kim³, Chong Kun Cheon ${ }^{4}$, Sang-Hyun Hwang ${ }^{5}$ and Ho-Young Kang ${ }^{1 *+}$

\begin{abstract}
Background: Array comparative genomic hybridization (CGH) is currently the most powerful method for detecting chromosomal alterations in pre and postnatal clinical cases. In this study, we developed a BAC based array CGH analysis platform for detecting whole genome DNA copy number changes including specific micro deletion and duplication chromosomal disorders. Additionally, we report our experience with the clinical implementation of our array CGH analysis platform. Array CGH was performed on 5080 pre and postnatal clinical samples from patients referred with a variety of clinical phenotypes.

Results: A total of 4073 prenatal cases (4033 amniotic fluid and 40 chorionic villi specimens) and 1007 postnatal cases (407 peripheral blood and 600 cord blood) were studied with complete concordance between array CGH, karyotype and fluorescence in situ hybridization results. Among 75 positive prenatal cases with DNA copy number variations, 60 had an aneuploidy, seven had a deletion, and eight had a duplication. Among 39 positive postnatal cases samples, five had an aneuploidy, 23 had a deletion, and 11 had a duplication.

Conclusions: This study demonstrates the utility of using our newly developed whole-genome array CGH as firsttier test in 5080 pre and postnatal cases. Array CGH has increased the ability to detect segmental deletion and duplication in patients with variable clinical features and is becoming a more powerful tool in pre and postnatal diagnostics.
\end{abstract}

\section{Background}

Array comparative genomic hybridization (CGH) was developed as a genome wide screening strategy for detecting DNA copy number changes mainly in chromosomal disorders and cancer research [1-4]. Chromosomal abnormalities are a major cause of congenital and developmental abnormalities in human genetic diseases including dysmorphic features, mental retardation and developmental delay, and multiple congenital anomalies. Karyotype analysis has been the gold standard for pre and postnatal diagnosis. Using traditional cytogenetic techniques, chromosomal imbalances such as aneuploidies and segmental abnormalities must be larger than about $3 \sim 5 \mathrm{Mb}$ to be detected by GTG banding. In the past two decades,

\footnotetext{
* Correspondence: mgmed@naver.com

+ Contributed equally

${ }^{1}$ MG MED, Inc., Seoul, Korea

Full list of author information is available at the end of the article
}

various traditional banding techniques have been combined with molecular cytogenetic technologies to improve the resolution at which genomic changes can be detected. Array CGH technology has higher resolution and excellent throughput when compared to conventional and molecular cytogenetics. In array $\mathrm{CGH}$, genomic DNA from the patient and reference are labeled with different fluorescent dyes and co-hybridized to an array matrix containing cloned DNA. The content of an array may include specific targeted regions of the genome or the entire genome arrayed on a single glass slide. Similar to conventional $\mathrm{CGH}$, genome imbalances are quantified by analyzing the ratio of the two fluorescent hybridizing signals. The resolution of array CGH is determined by the size and number of the clones placed on the array to interrogate genome copy number changes. Whole genome or targeted array CGH is a powerful tool to accurately detect subtelomeric rearrangements. Array CGH has higher resolution and
() Biomed Cental

(c) 2011 Park et al; licensee BioMed Central Ltd. This is an Open Access article distributed under the terms of the Creative Commons Attribution License (http://creativecommons.org/licenses/by/2.0), which permits unrestricted use, distribution, and reproduction in any medium, provided the original work is properly cited. 
powerful clinical utility when compared with conventional and other molecular cytogenetic technologies. Array CGH has successfully detected DNA copy number changes, and several groups have studied the clinical application of this technology in both prenatal and postnatal samples [5-9]. Recently, The International Standard Cytogenomic Array (ISCA) Consortium reported consensus statement on the use of chromosomal microarray as a first-tier diagnostic test in the evaluation of individuals with developmental delays and/or congenital anomalies [10,11]. Our group successfully developed and validated a bacterial artificial chromosome (BAC) based array CGH analysis platform including analysis software [12]. This BAC array CGH analysis platform is based on 1440 fluorescence in situ hybridization (FISH) verified BAC clones that were selected among 100,000 BAC clones constructed by the Asian Genome Project [13] and validated by end-sequencing and FISH. This array CGH contains whole genomic regions including 356 major cell-growth related genes and over 40 known DNA copy number change disorders.

In this study, we applied our newly developed array CGH platform to 5080 clinical pre and postnatal cases and identified 114 abnormal cases with 75 prenatal and 39 postnatal cases. Our results support previous reports of the utility of array $\mathrm{CGH}$ for detecting chromosomal DNA copy number variations in prenatal and postnatal clinical cases.

\section{Materials and methods}

\section{1) Clinical samples}

We analyzed the results obtained from 5080 clinical cases referred to MG MED laboratories for array CGH analysis between April 2007 and December 2009. We studied 4073 prenatal cases (4033 Amniotic Fluid [AF] and 40 Chorionic Villi [CV]) and 1007 postnatal cases (407 Peripheral Blood [PB] and 600 Cord Blood [CB]). The indications for the 4073 prenatal cases were family history, advanced maternal age, fetal ultrasound anomalies, elevated serum alpha fetoprotein, and parental anxiety. The indications for the 407 postnatal cases were mainly developmental delay, mental retardation, and multiple congenital abnormalities. The 600 postnatal cord blood samples were collected from the cord blood bank for detecting genomic imbalances, which were submitted by obstetricians, pediatricians, and geneticists. All samples were well prepared for experiments using previously described methods [12]. Appropriate ethical approval was obtained, and informed consent for the genetic testing was obtained from all patients.

\section{2) Development of the array CGH analysis platform}

We developed an BAC based array CGH analysis platform for detecting genomic imbalances in human genetic diseases [12]. Our array CGH chip consists of
1440 non-overlapping BAC clones (MACArray Karyo 1440 BAC-chip, Macrogen, Seoul, South Korea). A total of 1440 clone locations are shown on this website (http://www.macrogen.co.kr/eng/biochip/genelist_overview.html), which were selected among 100,000 BAC clones constructed by the Asian Genome Project $[13,14]$ and carefully mapped, end-sequenced, and fluorescently labeled by FISH. All clones were two-end sequenced using an ABI PRISM 3700 DNA Analyzer (Applied Biosystems, Foster City, CA), and their sequences were Blast analyzed and mapped according to their positions as described in the University of California, Santa Cruz (UCSC) human genome database (http://www.genome. ucsc.edu). Confirmation of the locus specificity of the chosen clones was performed by removing multiple locibinding clones by individual examination using standard FISH procedures as described previously.

\section{3) Array CGH and data analysis}

DNA was extracted from $\mathrm{AF}, \mathrm{CB}, \mathrm{PB}$ and $\mathrm{CV}$ using the PureGene kit (Gentra Systems, Minneapolis, MN). After extracting the DNA, we labeled 50 500 ng of both test and reference DNA with Cy 3- and Cy 5-dCTP (Perkin Elmer) by a random priming method using Exo-Klenow Fragment (Invitrogen, Carlsbad, CA) for $16 \mathrm{hr}$. labeled according to the manufacturer's recommendations. Reported here are pre and postnatal cases tested using the BAC chip. The array CGH chip data were analyzed using the chromofluor image analysis system (Array Analysis; Macrogen, South Korea). The slides contained 1440 human BAC clones including specific loci of more than 40 chromosomal disorders and 356 cell growth related genes from BAC libraries at a resolution average of $2.3 \mathrm{Mb}$ for the entire genome. The human DNA source for making the BAC library was human sperm derived from a Korean man. Each BAC clone was represented on an array as triplicate spots, and each array was scanned using a GenePix4000B scanner (Axon Instruments, Foster City, CA, USA) and analyzed with array software (MAC VIEWER, Macrogen, South Korea). Green (test) to red (reference) (G/R) ratios were automatically determined for each sample, and the normalized $G / R$ ratio represented the relative average number of copies of the sequence for those spots that were selected as controls. Spots with G/R ratios more than the mean plus 2.5 standard deviations (1.25) were considered amplifications or gains of the indicated copy number; less than the mean minus 2.5 deviations $(-0.75)$ were considered losses of the copy number.

\section{4) Karyotype and FISH with region-specific probes analyses}

The chromosome analysis was performed according to standard methods using cultured cells from amniotic 
fluid and peripheral blood samples obtained from the patient and available parents. Metaphase preparations were analyzed by G-banding techniques. FISH studies on interphase or metaphase spreads with specific probes were performed following the manufacturer's protocols (Macrogen). FISH was performed with specific BAC clones to confirm the array $\mathrm{CGH}$ analysis. FISH was performed mainly with two color probes; the specific $\mathrm{BAC}$ probes labeled with $\mathrm{Cy} 3$ (red) and the control probe (green) with FITC. The specific BAC probes were constructed using BAC clone DNA (NCBI build35). FISH was performed on metaphase chromosomes cultured from amniotic fluid and peripheral blood lymphocytes from each patients and available parents. Image acquisition of metaphase cells and subsequent karyotyping were performed using the CytoVision system (Applied Imaging, Santa Clara, CA, USA). A karyotype was characterized according to the conventions of the International System for Human Cytogenetic Nomenclature (ISCN, 2009).

\section{Results}

Array CGH is currently the most powerful method for simultaneously detecting genomic alterations. We performed whole genome array $\mathrm{CGH}$ using $\mathrm{CGH}$ array slides containing 1440 clones including about 40 chromosomal disorders specific loci and 356 cell growth related genes from BAC libraries in 5080 pre and postnatal cases (Table 1 ). We simultaneously performed FISH and a G-banding analysis to confirm abnormal array $\mathrm{CGH}$ results. In all prenatal cases, we performed array $\mathrm{CGH}$ analysis and concurrent karyotype analysis. We detailed genotype-phenotype correlations as far as possible in postnatal cases.

Of 4073 prenatal cases (4033 AF and 40 CV specimens), we identified 75 positive cases $(75 / 4073=1.8 \%)$ with DNA copy number variations; 60 had an aneuploidy, seven had a deletion, and eight had a duplication (Table 2). Thirty-six cases had an autosomal aneuploidy, and 24 cases had a sex chromosome aneuploidy. The detection rate of overall chromosomal rearrangements including balanced translocations and inversions by karyotype analysis was 3.8\% (155/4073). In prenatal cases, we identified deletion/micro deletion breakpoints (2q13, 7q11.23, 17p11.2, Xp22.31, and Xq24qter) and duplication/micro duplication chromosomes (1q42q44, 15q11.2q12, 21q11.2, Xp22.31, Xp21.2, and Xq27.2qter). A heterozygous micro deletion at $2 \mathrm{q} 13$, which includes the Joubert syndrome (2q13 homozygous deletion) critical region, was observed in two cases. The array $\mathrm{CGH}$ results were normal in two marker chromosome cases. The marker chromosomes seemed to consist of mainly heterochromatin or this may have been due to the limited array CGH coverage.

A total of 1007 postnatal cases (407 PB and $600 \mathrm{CB}$ ) were studied with complete concordance between array $\mathrm{CGH}$, karyotype and FISH results. Among the postnatal cases with 39 positive cases, five had an aneuploidy, 23 had a deletion, and 11 had a duplication (Table 3). We identified breakpoints on 17 types of deletion/micro deletion and seven types of duplication/micro duplication chromosomes. The most common indications for referral in the $407 \mathrm{~PB}$ cases were developmental delay, mental retardation, congenital abnormalities, and dysmorphic features. We identified 34 deletion/duplication cases $(34 / 407=8.3 \%)$ in $407 \mathrm{~PB}$ cases with clinical indications. In $600 \mathrm{CB}$ cases for screening genomic imbalances from the cord blood bank, we found four deletion (15q11.2, 22q11.2, and Xp11.2petr) cases and one duplication $(2 q 13)$ case $(5 / 600=0.83 \%)$. Thirty-four cases had segmental gains or losses associated with chromosomal deletion (micro deletion) or duplication (micro duplication), including Wolf-Hirschhorn syndrome (WHS)(4p16.3), Cri-du-chat syndrome (5p15.3), Soto's syndrome (5q35.3), William's syndrome (7q11.23), Digeorge syndrome 2 (10p14), Prader Willi/Angelman syndrome (15q11.2), Digeorge syndrome (22q11.2), steroid sulfatase deficiency (Xp22.31), Cat eye syndrome (22q11.2), and Emanuel syndrome (22q11, 11q23). We performed array $\mathrm{CGH}$, and the molecular cytogenetic results are shown in Figure 1 (examples of prenatal deletion/duplication cases) and 2 (examples of postnatal deletion/duplication cases). We also found clinical features in the postnatal cases. For

Table 1 Summary of array CGH analysis in 5080 cases

\begin{tabular}{|c|c|c|c|c|c|c|}
\hline & & \multicolumn{3}{|c|}{ 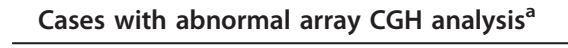 } & \multirow[t]{2}{*}{ Total (N) } & \multirow[t]{2}{*}{ Detection rate (\%) } \\
\hline & & Aneuploidy (N) & Deletion (N) & Duplication (N) & & \\
\hline Prenatal cases $^{\mathrm{b}}(\mathrm{N}=4073)$ & & 60 & 7 & 8 & 75 & 1.8 \\
\hline \multirow[t]{2}{*}{ Postnatal cases $(\mathrm{N}=1007)$} & PB with clinical indications ${ }^{c}(N=407)$ & 5 & 19 & 10 & 34 & 8.3 \\
\hline & $C B(N=600)$ & 0 & 4 & 1 & 5 & 0.83 \\
\hline Total & 5080 & 65 & 30 & 19 & 114 & 2.24 \\
\hline
\end{tabular}


Table 2 Summary of array CGH and cytogenetic analyses in 4073 prenatal cases ${ }^{\mathrm{a}}$

\begin{tabular}{|c|c|c|}
\hline Case (number) & Array CGH analysis ${ }^{\mathbf{b}}$ & Cytogenetic analyses $^{c}$ \\
\hline & & Aneuploidy \\
\hline $1(1)$ & Duplication of whole chr.13 & Trisomy 13 \\
\hline $2(7)$ & Duplication of whole chr.18 & Trisomy 18 \\
\hline $3(28)$ & Duplication of whole chr.21 & Trisomy 21 \\
\hline $4(6)$ & Duplication of whole chr.X & $47, X X X$ \\
\hline $5(7)$ & Duplication of whole chr.X & $47, X X Y$ \\
\hline $6(1)$ & Duplication of whole chr.X & Mos 47,XXY [18]/48,XXY,+17 [2] \\
\hline $7(1)$ & Copy number ratio of less than one copy loss at chr. 9 & Mos 47,XXX [29]/48,XXX,+9 [11] \\
\hline $8(1)$ & Copy number ratio of less than one copy loss at chr.X & Mos 47,XXY [32]/46,XY [8] \\
\hline $9(1)$ & Duplication of whole chr.X and 18 & $48, X X Y,+18$ \\
\hline $10(1)$ & Duplication of long arm at Xq10qter/whole chr. 9 & $47, X, i(X)(q 10),+9$ \\
\hline $11(4)$ & Deletion of whole chr.X & $45, X$ \\
\hline $12(1)$ & Copy number ratio of less than one copy loss at chr.X & Mos 45,X [22]/46,XX [8] \\
\hline \multirow[t]{2}{*}{$13(1)$} & Copy number ratio of less than one copy loss at chr.X & $\operatorname{Mos} 45, X[10] / 46, X X[20]$ \\
\hline & & Deletion/Microdeletion \\
\hline $14(2)$ & Deletion of $0.5 \mathrm{Mb}$ at $2 \mathrm{q} 13$ & 46,XX,ish del(2)(q13q13)(NPHP1-) \\
\hline $15(1)$ & Deletion of $0.4 \mathrm{Mb}$ at $7 \mathrm{q} 11.23$ & 46,XY.ish del(7)(q11.23q11.23)(ELN-) \\
\hline \multirow[t]{2}{*}{$16(2)$} & Deletion of $0.4 \mathrm{Mb}$ at $17 \mathrm{p} 11.2$ & 46,XX.ish del(17)(p11.2p11.2)(D17S29-) \\
\hline & Deletion of $0.4 \mathrm{Mb}$ at $17 \mathrm{p} 11.2$ & 46,XY.ish del(17)(p11.2p11.2)(D17S29-) \\
\hline $17(1)$ & Deletion of $0.5 \mathrm{Mb}$ at Xp22.31 & 46,XY.ish del(X)(p22.31p22.31)(STS-) \\
\hline \multirow[t]{2}{*}{$18(1)$} & Deletion of $25 \mathrm{Mb}$ at Xq24qter & $46, X$, del $(X)(q 24 q$ ter $)$ \\
\hline & & Duplication/Microduplication \\
\hline $19(1)$ & Duplication of $10 \mathrm{Mb}$ at 1q42q44 & 46,XY.ish dup(1)(q42.1q44)(D1S491+) \\
\hline $20(2)$ & Duplication of $1.3 \mathrm{Mb}$ at $15 \mathrm{q} 11.2 \mathrm{q} 12$ & 46,XX.ish dup(15)(q11.2q12)(SNRPN+) \\
\hline $21(2)$ & Duplication of $1.5 \mathrm{Mb}$ at $22 \mathrm{q} 11.2$ & 46,XY.ish dup(22)(q11.2q11.2)(COMT+) \\
\hline $22(1)$ & Duplication of $0.5 \mathrm{Mb}$ at $\mathrm{Xp} 22.31$ & 46,XX.ish dup(X)(p22.31p22.31)(KAL1+) \\
\hline $23(1)$ & Duplication of $0.5 \mathrm{Mb}$ at Xp21.2 & 46,XY.ish dup(X)(p21.2p21.2)(DMD+) \\
\hline \multirow[t]{2}{*}{$24(1)$} & Duplication of $5 \mathrm{Mb}$ at $\mathrm{Xq} 27.2 \mathrm{qter}$. & 46,XY,ish dup (X)(q27.2qter)(DX904+) \\
\hline & & Small supernumerary marker chromosome \\
\hline \multirow[t]{2}{*}{$25(2)$} & Normal & $47, X X,+$ mar \\
\hline & Normal & $47, X Y,+$ mar \\
\hline $26(80)$ & Normal & Others $^{d}$ \\
\hline
\end{tabular}

${ }^{a}$ Data compiled from array CGH and cytogenetic analyses in $4033 \mathrm{AF}$ and $40 \mathrm{CV}$ by the major indications for prenatal testing such as advanced maternal age, fetal ultrasound anomalies, and elevated serum alpha fetoprotein ${ }^{\mathrm{b}} \log _{2}$ mean green/red (G/R) ratios more than the mean +2.5 SD ( 0.25$)$ were considered high amplifications or gains of the indicated copy number, and less than the mean -2.5 SD ( -2.5) were considered high losses of the copy number. ${ }^{C}$ performed by karyotype and FISH analyses. FISH analyses were performed using specific BAC clones. ${ }^{\mathrm{d}}$ Structural balanced arrangements (inversion and translocation).

example, the postnatal case 10 patient with Sotos syndrome was a 1.1-year-old male with a birth weight of $4.1 \mathrm{~kg}$. He had typical facial features including macrocephaly, sparseness of frontotemporal hair, high bossed forehead, a long narrow face and prominent narrow jaw, developmental delay, overgrowth, abnormally large hands, and a café au lait spot. We identified not only simple deletion and duplication but also multiple copy number abnormalities including various chromosomal rearrangements (postnatal cases 4, 24, 27, and 30). Additionally, postnatal case 4 was identified with multiple rearrangements. Although we found a 2q14q21.1 deletion using array CGH, we were able to characterize accurate cytogenetic features as $46, \mathrm{XY}, \operatorname{der}(2) \mathrm{t}(2 ; 6)$ (q21.1;q23)inv(2)(q14.1q37) and $\operatorname{der}(6) t(2 ; 6)(q 21.1 ; q 23)$ by concurrent karyotype analysis (data not shown). In case 30 , we identified two chromosomes involved as a small supernumerary marker chromosome (sSMC) as 47,XX, +der(22) $\mathrm{t}(11 ; 22)(\mathrm{q} 23 ; \mathrm{q} 11)$ with mental retardation (Figure 2).

\section{Discussion}

Array CGH offers a high-resolution genome analysis in a clinical setting [15]. Currently, many commercial and academic laboratories have used BAC-based array, oligonucleotide-based array or SNP-based arrays. Array resolution is dependent on the number and types of probes used and how they are designed on the genome. Current commercial BAC arrays (targeted or whole genome) generally have 600 5200 BAC clones (e.g. PerkinElmer). Our whole-genome BAC array CGH platform is based on 1440 fluorescence in situ hybridization (FISH) 
Table 3 Summary of array CGH and cytogenetic analyses in 1007 postnatal cases ${ }^{\mathrm{a}}$

\begin{tabular}{|c|c|c|c|c|}
\hline $\begin{array}{l}\text { Case } \\
\text { (number) }\end{array}$ & Array CGH analysis ${ }^{\mathrm{b}}$ & Cytogenetic analyses $^{c}$ & $\begin{array}{l}\text { Involved } \\
\text { Gene(s) }\end{array}$ & $\begin{array}{c}\text { Clinical } \\
\text { indications }\end{array}$ \\
\hline & & Aneuploidy & & \\
\hline $1(3)$ & Duplication of whole chr.21 & Trisomy 21 & & $\mathrm{DD}, \mathrm{MR}$ \\
\hline 2 & Duplication of whole chr.X & $47, X X Y$ & & $\begin{array}{l}\text { Klinefelter's } \\
\text { syndrome }\end{array}$ \\
\hline \multirow[t]{2}{*}{3} & Duplication of whole chr.Y & $47, X Y Y$ & & \\
\hline & & Deletion/Microdeletion & & \\
\hline \multirow[t]{2}{*}{4} & Deletion of $15 \mathrm{Mb}$ at $2 \mathrm{q} 14 \mathrm{q} 21.1$ & $46, X Y, \operatorname{der}(2) t(2 ; 6)(q 21.1 ; q 23)$ & Multiple & $\mathrm{DD}, \mathrm{MR}$ \\
\hline & & $\operatorname{inv}(2)(q 14.1 q 37), \operatorname{der}(6) t(2 ; 6)(q 21.1 ; q 23)$ & & \\
\hline 5 & Deletion of $1 \mathrm{Mb}$ at $3 \mathrm{q} 23 \mathrm{q} 25$ & 46,XY. ish del(3)(q23q25)(D3S1557-) & $\mathrm{ZIC1}, 4$ & $D D, I A, C P$ \\
\hline 6 & Deletion of $0.5 \mathrm{Mb}$ at $3 \mathrm{q} 29$ & 46,XY, ish del(3)(q29q29)(MF12-) & PAK2,DLG1 & DD \\
\hline 7 & Deletion of $1 \mathrm{Mb}$ at $4 \mathrm{p} 16.3$ & 46,XX, del(4)(p16.3p16.3) & WHSC1 & WHS \\
\hline 8 & Deletion of $0.8 \mathrm{Mb}$ at $4 \mathrm{q} 35.1$ qter & 46,XX.ish del(4)(q35.1qter)(D4S187-) & Multiple & DD \\
\hline $9(2)$ & Deletion of $0.8 \mathrm{Mb}$ at $5 p 15.3$ & 46,XY.ish del(5)(p15.3p15.3)(D5S2774-) & Multiple & $\mathrm{DD}, \mathrm{MR}$ \\
\hline 10 & Deletion of $0.5 \mathrm{Mb}$ at $5 \mathrm{q} 35.2$ & 46,XY.ish del(5)(q35.2q35.2)(NSD1-) & NSD1 & Sotos syndrome \\
\hline $11(2)$ & Deletion of $0.4 \mathrm{Mb}$ at $7 q 11.23$ & 46,XY.ish del(7)(q11.23q11.23)(ELN-) & ELN & $\begin{array}{l}\text { Williams } \\
\text { syndrome }\end{array}$ \\
\hline 12 & Deletion of $5 \mathrm{Mb}$ at 10p12.4p14 & $46, \mathrm{XY}$. ish del(10)(p12.4p14)(D10S585-) & NEBL & DGS2 \\
\hline 13 & Deletion of $0.5 \mathrm{Mb}$ at $12 \mathrm{q} 14.3$ & 46,XY.ish del(12)(q14.3q14.3)(D12S1448- ) & LEMD3 & DD \\
\hline 14 & Deletion of $5 \mathrm{Mb}$ at 14q32.2qter & 46,XX.ish del(14)(q32.2qter)(SHGC172944-) & Multiple & DD \\
\hline $15(2)$ & Deletion of $0.5 \mathrm{Mb}$ at $15 \mathrm{q} 11.2 \mathrm{q} 11.2$ & 46,XY.ish del(15)(q11.2q11.2)(SNRPN-) & SNRPN & PWS \\
\hline 16 & Deletion of $0.4 \mathrm{Mb}$ at 17p11.2 & 46,XY.ish del(17)(p11.2p11.2)(PMP22-) & PMP22 & \\
\hline 17 & Deletion of $0.8 \mathrm{Mb}$ at $18 \mathrm{p} 11.32$ & $46, X X$, ring $(18)(p 11.32 q 23)$ & Multiple & DD \\
\hline $18(2)$ & Deletion of $2.5 \mathrm{Mb}$ at $22 \mathrm{q} 11.2$ & 46,XY.ish del(22)(q11.2q11.2)(D22S75-) & TBX1 & DGS \\
\hline $19(3)$ & Deletion of $0.5 \mathrm{Mb}$ at Xp22.31 & 46,X.ish del(X)(p22.31p22.31)(STS-) & STS & ichthyosis, ADHD \\
\hline \multirow[t]{2}{*}{20} & Deletion of $1 \mathrm{Mb}$ at Yq11.2qter & 46,X.ish del(Y)(q11.2qter)(CDY1-) & CDY1 & Azoospermia \\
\hline & & Duplication/Microduplication & & \\
\hline 21 & Duplication of $5 \mathrm{Mb}$ at $1 \mathrm{q} 42.2 \mathrm{qter}$ & 46,XY.ish dup(1)(q42.2qter)(D1S204+) & Multiple & \\
\hline 22 & Duplication of $0.5 \mathrm{Mb}$ at $2 \mathrm{q} 13$ & 46,XX.ish dup(2)(q13q13)(NPHP1+) & NPHP1 & \\
\hline 23 & Duplication of $3 \mathrm{Mb}$ at $15 \mathrm{q} 11.2 \mathrm{q} 12$ & 46,XX.ish dup(15)(q11.2q12)(SNRPN+) & SNRPN & DD,Autism,PD \\
\hline 24 & $\begin{array}{l}\text { Duplication of } 0.9 \mathrm{Mb} \text { at } 21 \mathrm{q} 22 \text { \& Deletion of } \\
0.5 \mathrm{Mb} \text { at } 21 \mathrm{q} 22\end{array}$ & $\begin{array}{c}\text { 46,XY.ish del(21)(q22q22), dup(21)(q22q22) } \\
\text { (D21S1898+) }\end{array}$ & Multiple & DD \\
\hline $25(2)$ & Duplication of $0.9 \mathrm{Mb}$ at $22 \mathrm{q} 11.2$ & 46,XY.ish dup(22)(q11.2q11.2)(D22S75+) & TBX1 & DD \\
\hline 26 & Duplication of $0.9 \mathrm{Mb}$ at Yp11.2pter & 46,X.ish i(Y)(p11.2pter)(DYS289+) & SRY & Azoospermia \\
\hline \multirow[t]{3}{*}{27} & Duplication of $3 \mathrm{Mb}$ at Yq11.2qter \& & 46,X.ish del(X)(p22.31p22.31), & STS & $\begin{array}{l}\text { Short stature, } \\
\text { ADHD }\end{array}$ \\
\hline & Deletion of $0.5 \mathrm{Mb}$ at $\mathrm{Xp} 22.31$ & $\operatorname{dup}(Y)(q 11.2 q$ ter)(STS-,CDY1+) & CDY1 & \\
\hline & & Small supernumerary marker chromosome & & \\
\hline 28 & Duplication of $3 \mathrm{Mb}$ at $18 \mathrm{p} 11.2 \mathrm{p} 11.3$ & $47, X Y,+\operatorname{der}(18)(\mathrm{p} 11.2 \mathrm{p} 11.32)$ & Multiple & DD \\
\hline 29 & Duplication of $0.9 \mathrm{Mb}$ at $22 \mathrm{q} 11.2 \mathrm{qter}$ & 47,XY,+mar.ish i(22)(q11.2qter)(D22S43+) & Multiple & $\begin{array}{l}\text { Cat eye } \\
\text { syndrome }\end{array}$ \\
\hline 30 & Duplication of $2 \mathrm{Mb}$ at $22 \mathrm{q} 11 \& 3 \mathrm{Mb}$ at $11 \mathrm{q} 23$ & $\begin{array}{c}\text { 47,XX,+mar.ish }+\operatorname{der}(22) t(11 ; 22)(q 23 ; q 11)(C E S+, \\
\text { D11S4145+) }\end{array}$ & Multiple & $\begin{array}{l}\text { Emanuel } \\
\text { syndrome }\end{array}$ \\
\hline
\end{tabular}

DD, developmental delay; MR, mental retardation; IA, imperforated anus; CP, cleft palate; WHS, Wolf-Hirschhorn syndrome; DGS, DiGeorge syndrome; PWS, Prader-Willi syndrome; ADHD, Attention Deficit Hyperactivity Disorder; PD, Pigmentation disorder

${ }^{\mathrm{a}}$ Data compiled from $407 \mathrm{~PB}$ and $600 \mathrm{CB}$.

${ }^{\mathrm{b}} \log _{2}$ mean green/red ratios more than the mean +2.5 SD $(\sim 0.25)$ were considered high amplifications or gains of the indicated copy number, and less than the mean -2.5 SD ( - -0.25) were considered high losses of the copy number.

'performed by karyotype and FISH analyses. FISH analyses were performed using specific BAC clones.

verified BAC clones, which were selected among 100,000 BAC clones constructed by the Asian Genome Project $[13,14]$ and validated by end-sequencing and FISH. Therefore, our abnormal array CGH results were able to be confirmed by FISH, that BAC clones were available to clinically relevant turnaround times.

In this study, we showed the utility of our whole-genome BAC-based array CGH platform in a large 


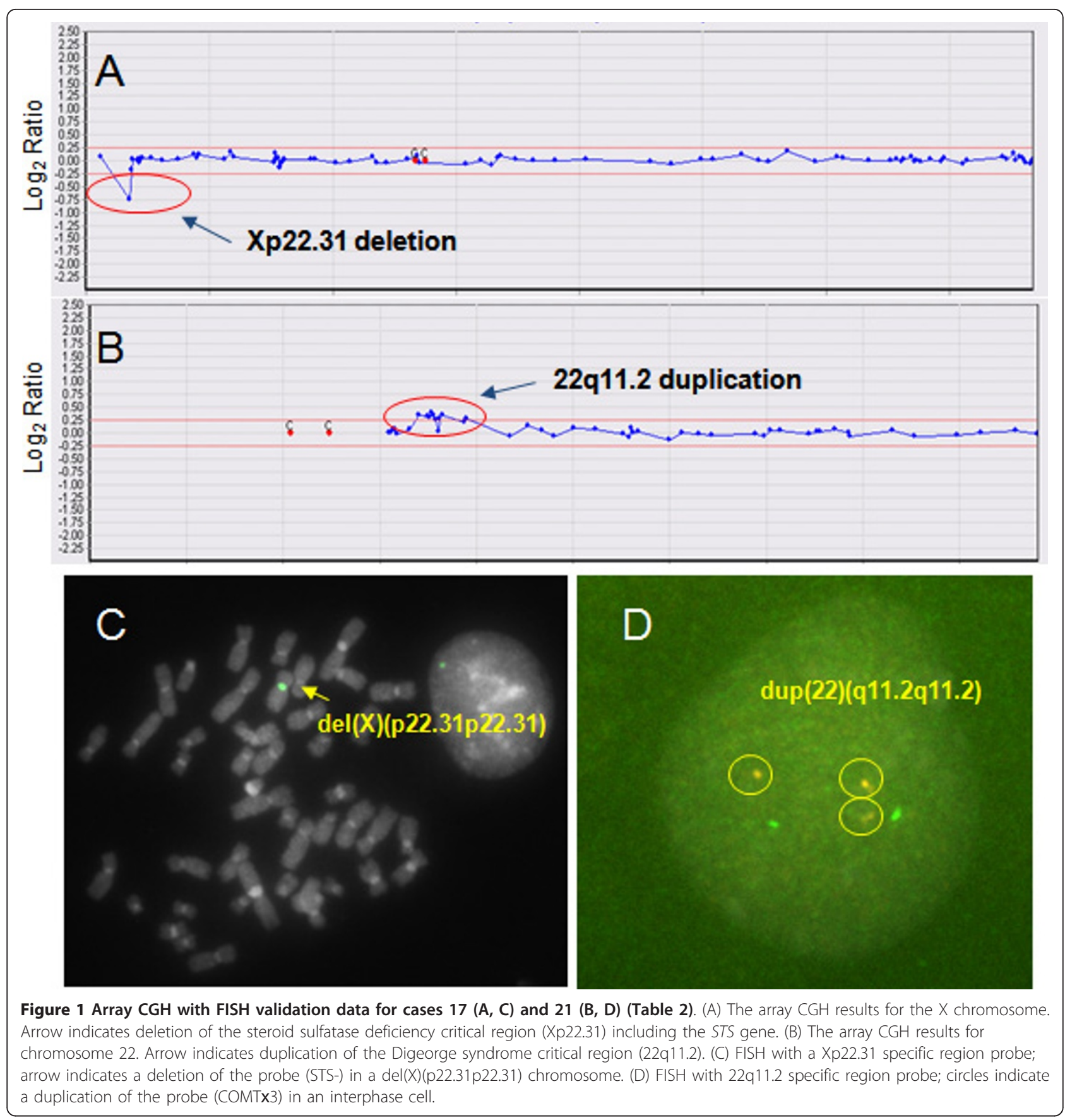

collection of clinical cases. Previous prenatal studies reported chromosomal abnormalities in $\sim 1.3 \%$ of cases [16]. Furthermore, previous postnatal studies have shown that array $\mathrm{CGH}$ with cytogenetic analysis detects clinically significant chromosome abnormalities in $\sim 7 \%$ of children referred for cytogenetic testing [16]. In this study, the prenatal detection rate was $1.8 \%(75 / 4073)$ and the postnatal detection rate with clinical indications was $8.3 \%$ (34/407) using array CGH (Table 1). These results are consistent with previous reports [17]. In prenatal cases, we identified 11 types with DNA copy number changes including five micro deletions and six micro duplications. Because these micro deletion/duplication chromosomal abnormalities could not be detected by conventional cytogenetic methods, array $\mathrm{CGH}$ analysis was more useful. We also classified the pathogenic variants. In case 14 (deletion at 2q13), we identified a heterozygous deletion using FISH analysis. Homozygous deletions of this locus (2q13 deletion) are pathogenic variants related to Joubert syndrome [18]. 


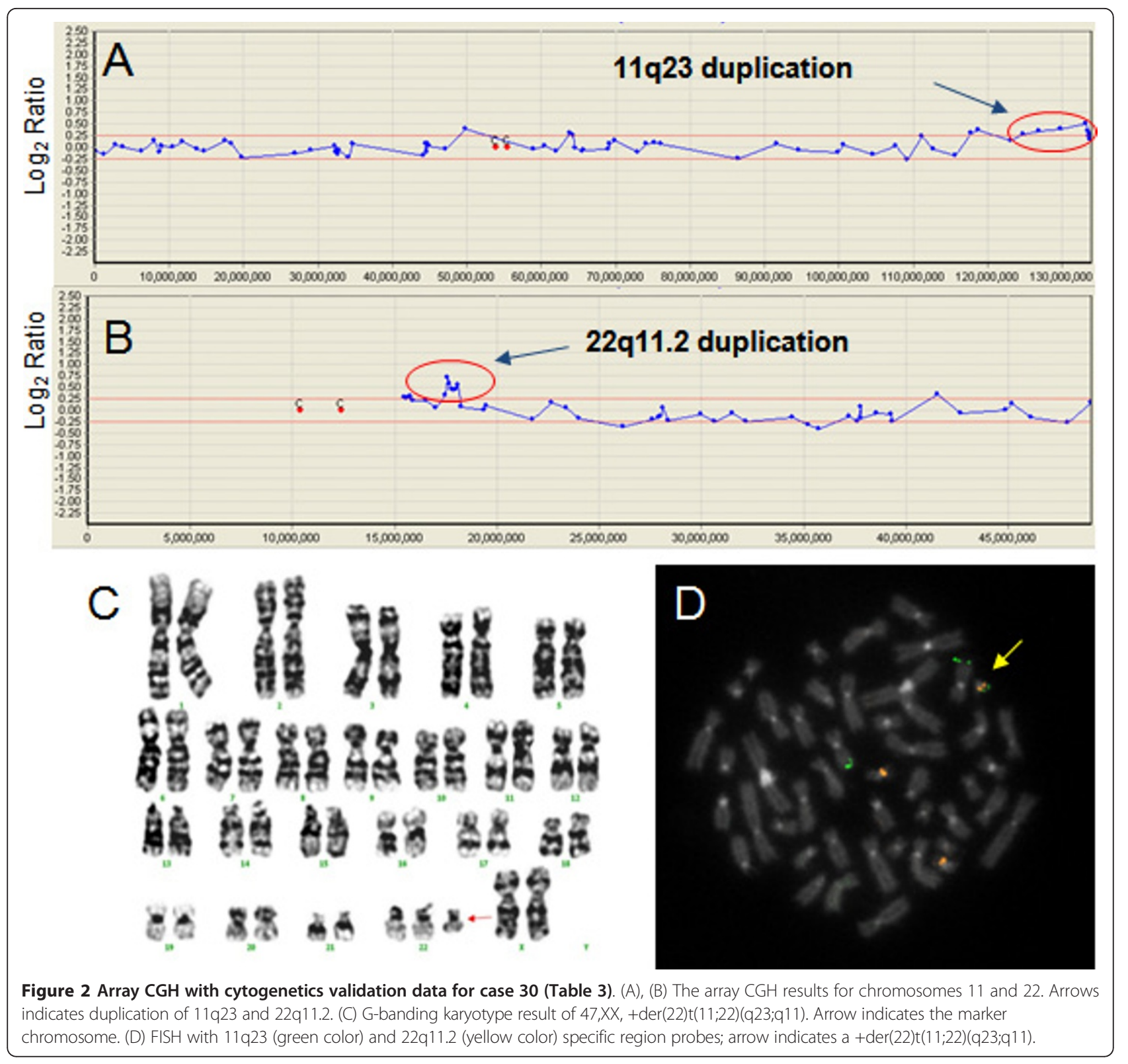

We also identified $15 \mathrm{q} 11.2$ and $22 \mathrm{q} 11.2$ duplications (cases 20 and 21). These duplication copy number variation phenotypes appear to be generally mild and highly variable; findings ranged from apparently normal to mental retardation, growth retardation, and autism (15q11.2 duplication). Therefore, prenatal array CGH results must be evaluated whether the results show benign variants or pathogenic variants. Currently, many useful copy number variation data base websites are available. For example, the Database of Genomic Variants (http://projects.tcag.ca/variation/), DECIPHER (http://decipher.sanger.ac.uk/), and Genereviews (http:// www.genetests.org/), which is a more clinically useful website that lists the associated genetic diseases including phenotypes, genotypes, and clinical management of pathogenic copy number variant diseases. Many known micro deletion syndromes are expressed by incomplete penetrance [19], whereas duplications generally produce milder and, therefore, less identifiable phenotypes than counterpart deletions [20]. A previous study suggested an effective general algorithm for clinical testing using array CGH [21]. Moreover, practical guidelines for array $\mathrm{CGH}$ have been issued by the American College of Medical Genetics [22,23]. It is important that, with the exception of purported benign copy number variables (CNVs), all regions showing abnormal copy number 
findings be characterized by FISH and parental studies. An increase in the prenatal detection rate of chromosome abnormalities would benefit patients seeking genetic testing prior to delivery $[24,25]$.

In postnatal cases, we identified breakpoints on 17 types of deletion/micro deletion, seven types of duplication/micro duplication chromosomes and three sSMC types. Among the 39 positive postnatal cases, five had an aneuploidy, 23 had a deletion, and 11 had a duplication (Table 3). Most postnatal cases had clinical indications with developmental delay or mental retardation. Therefore, detection rates of chromosomal abnormalities using array CGH analysis are generally higher than prenatal cases. In this study, we analyzed various patients with clinical indications and/or unknown specific indications. We observed a 3q24 deletion in a patient (case 5) with developmental delay, imperforated anus, and cleft palate. Deletion of the 3q24-q26 region including the Dandy-Walker malformations (DWM) critical region (3q24) appears to be associated with a somewhat similar constellation of findings including craniofacial dysmorphism (broad and depressed nasal bridge and low set posteriorly rotated ears), mental retardation, congenital heart defects, and central nervous system malformations [26]. A previous study reported the critical region associated with DWM, which encompasses the ZIC1 and ZIC4 genes, by mapping the 3q24 interstitial deletions in several individuals with DWM [27]. In case 10 , we identified a micro deletion of the $5 \mathrm{q} 35$ region including the NSD1 gene in one Korean patient with Sotos syndrome (Figure 3). The most common mutation $(50 \%)$ was a micro deletion of the $5 \mathrm{q} 35$ region including NSD1 in Japanese patients with Sotos syndrome, while, in the UK, approximately $70 \%$ of patients with Soto syndrome have NSD1 point mutations, and only $10 \%$ of the patients have a micro deletion of the $5 \mathrm{q} 35$ region [28]. Therefore, further studies will be necessary for a better understanding of Sotos syndrome in Korean patients. The most commonly observed deletions were in the Xp22.31 region. Our patients with Xp22.31 (cases 19 and 27) appeared to be associated with ichthyosis, short stature, and attention deficit hyperactivity disorder (ADHD). The Xp22.31 deletion, causing loss of function of the STS gene, is associated with steroid sulfatase deficiency in males. The STS gene encodes steroid sulfatase, a membrane-bound microsomal enzyme that is ubiquitously expressed and hydrolyzes several 3-beta-hydroxysteroid sulfates, which serve as metabolic precursors for estrogens, androgens, and cholesterol [29]. A previous study reported on a patient with a Xp22.3 interstitial deletion that had ichthyosis, dysmorphic features, and mental retardation with ADHD [30]. We identified duplication cases at $15 \mathrm{q} 11.2 \mathrm{q} 12$ with developmental delay, autism, and pigmentation disorder (Figure 3). A previous study reported that this patient had infantile autism with cytogenetic abnormalities on chromosomal region 15q11-q13, as reported in patients with autistic disorder [31]. We identified three marker chromosome origins (11, 18, and 22 chromosome segments). sSMC origin analysis is very important for evaluating clinical phenotypes. The marker chromosome origin and size appear to result in variable phenotypes [32]. In our study, we identified a 22q11.2 duplication including the CES gene and two chromosomes involved in derivative translocation marker chromosome (22q11\&11q23 duplication) (Figure 2). This sSMC, $\operatorname{der}(22) \mathrm{t}(11 ; 22)(\mathrm{q} 23 ; \mathrm{q} 11)$, is related to Emanuel syndrome, which is characterized by severe mental retardation, microcephaly, failure to thrive, preauricular tag or sinus, ear anomalies, and cleft or high-arched palate [33]. These array CGH and other cytogenetic findings are consistent with the clinical phenotypes of Cat eye syndrome and Emmanuel syndrome with mental retardation. We also identified CNVs (2q13 duplication and 4q32 duplication) in phenotypically nor$\mathrm{mal}$ individuals from cord bank blood. The clinical significance of the $2 \mathrm{q} 13$ duplication is still emerging, as these copy number variations are also found in phenotypically normal and control individuals [34]. Duplication of $4 \mathrm{q} 32$ is a benign copy number variation represented in a copy number variation database (http://projects. tcag.ca/variation/).

And also, it is important to address some of the limitations of array CGH before this test is considered for clinical diagnosis as a first line test. Array CGH does not detect polyploidy, balanced translocations, inversions and low level mosaicims. Marker chromosomes may also be missed, depending on the size, marker composition and array coverage of the specific chromosomal region present on the marker chromosome. And also we must consider various limitations of array CGH testing (e.g. point mutations, uniparental disomy and appropriate turnaround times). Therefore, genetics laboratories must be capable of performing array CGH and concurrent conventional cytogenetic analyses (G-banding and FISH) including molecular genetic analyses (DNA sequencing etc.) and also clinical geneticists offer appropriate genetic counseling including interpretation of results and limitations of test for patients and family members.

\section{Conclusions}

This study demonstrated that our newly developed array CGH platform is very useful for clinical implementation using whole-genome array CGH as first-tier test in 5080 pre and postnatal cases. The application of array CGH with more extended coverage at disease specific regions and concurrent appropriate other cytogenetic analyses such as karyotype and FISH will be useful to 

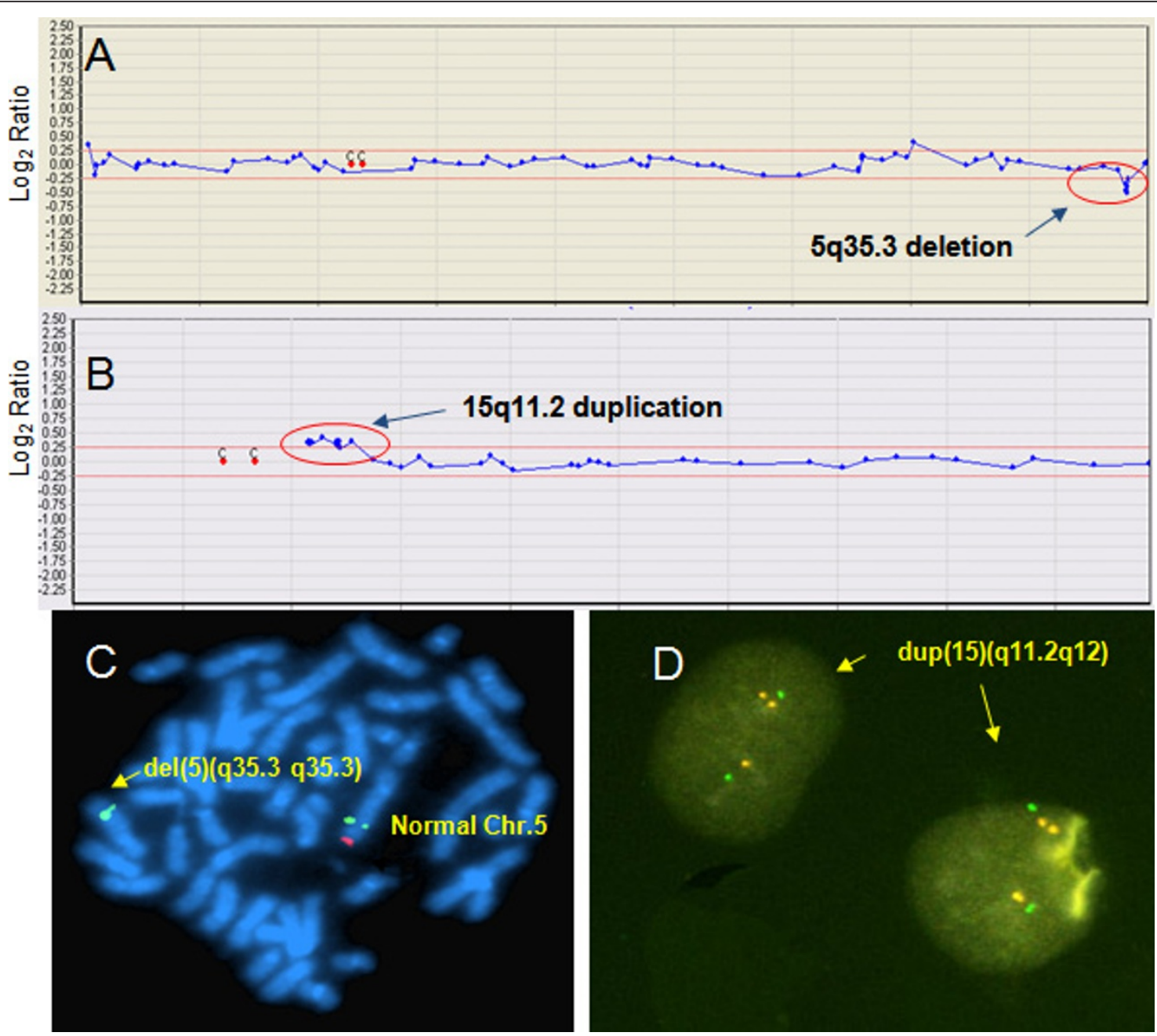

Figure 3 Array CGH with FISH validation data for cases 10 (A, C) and 23 (B, D) (Table 3). (A) The array CGH results for chromosome 5. Arrow indicates deletion of the Sotos syndrome critical region (5q35.3), including the NSD1 gene. (B) The array CGH results for chromosome 15. Arrow indicates duplication of the PWS/AS syndrome critical region (15q11.2). (C) FISH with a $5 q 35.3$ specific region probe; arrow indicates a deletion of the probe (NSD1-) in a del(5)(q35.3q35.3) chromosome. Deletion of the NSD1 gene region (red signal) was observed by FISH analysis, 46, XY, ish del(5)(q35.3q35.3)(D5S404+, NSD1-) (D) FISH with 15q11.2 specific region probe; arrows indicate a duplication of the probe (SNRPNx3) in interphase cells.

characterize various chromosomal disorders. Furthermore, the newly developed array CGH analysis platform will lead to a new understanding of genomic disorders with DNA copy number changes and their relationship to genotype and phenotype. Additionally, functional studies based on the identity of the involved genes are necessary for a further understanding of the mechanism related to contiguous genes on deletion and duplication loci in the development and/or progression of various DNA copy number change disorders.

\section{Acknowledgements}

We thank Dr. He doo Chung for his contribution to clinical validation and our clinical colleagues for supporting this work. We are grateful to other laboratory members for their enthusiastic participation.

\section{Author details}

${ }^{1}$ MG MED, Inc., Seoul, Korea. ${ }^{2}$ MACROGEN, Inc, Seoul, Korea. ${ }^{3}$ Department of Medical Genetics, Ajou University School of Medicine, Suwon, Korea. ${ }^{4}$ Department of Pediatrics, School of Medicine, Pusan National University Children's Hospital, Yangsan, Korea. ${ }^{5}$ Department of Laboratory Medicine, Center for Diagnostic Oncology, National Cancer Center, Gyeonggi-do, Korea.

\section{Authors' contributions}

SJP drafted the manuscript and analysed the data for the paper. EHJ performed array CGH. RSR performed karyotyping and FISH. HWK performed FISH, relevant confirmations and participated in validation work on the BAC array CGH platform. JMK, HJK, CKC and SHH provided clinical information, evaluation and advice. HYK conceived of the study, performed data analysis and also approved the manuscript. All authors read and approved the final manuscript.

\section{Competing interest statement}

The authors declare that they have no competing interests. 
Received: 30 March 2011 Accepted: 9 May 2011 Published: 9 May 2011

\section{References}

1. Park SJ, Jeong SY, Kim HJ: Y chromosome loss and other genomic alterations in hepatocellular carcinoma cell lines analyzed by CGH and CGH array. Cancer Genet Cytogenet 2006, 166:56-64.

2. Bejjani BA, Shaffer LG: Clinical utility of contemporary molecular cytogenetics. Annu Rev Genomics Hum Genet 2008, 9:71-86.

3. Shinawi M, Cheung SW: The array CGH and its clinical applications. Drug Discov Today 2008, 13:760-770

4. Albertson DG, Pinkel D: Genomic microarrays in human genetic disease and cancer. Hum Mol Genet 2003, 12:R145-152, Spec No 2

5. Lu X, Shaw CA, Patel A, Li J, Cooper ML, Wells WR, Sullivan CM, Sahoo T, Yatsenko SA, Bacino CA, et al: Clinical implementation of chromosomal microarray analysis: summary of 2513 postnatal cases. PLoS One 2007, 2 e327.

6. Shao L, Shaw CA, Lu XY, Sahoo T, Bacino CA, Lalani SR, Stankiewicz P, Yatsenko SA, Li Y, Neill S, et al: Identification of chromosome abnormalities in subtelomeric regions by microarray analysis: a study of 5,380 cases. Am J Med Genet A 2008, 146A:2242-2251.

7. Rickman L, Fiegler $H$, Shaw-Smith C, Nash R, Cirigliano V, Voglino G, Ng BL, Scott C, Whittaker J, Adinolfi M, et al: Prenatal detection of unbalanced chromosomal rearrangements by array CGH. J Med Genet 2006, 43:353-361.

8. Evangelidou P, Sismani C, loannides M, Christodoulou C, Koumbaris G, Kallikas I, Georgiou I, Velissariou V, Patsalis PC: Clinical application of whole-genome array CGH during prenatal diagnosis: Study of 25 selected pregnancies with abnormal ultrasound findings or apparently balanced structural aberrations. Mol Cytogenet 2010, 3:24.

9. Ahn JW, Mann K, Walsh S, Shehab M, Hoang S, Docherty Z, Mohammed S, Mackie Ogilvie C: Validation and implementation of array comparative genomic hybridisation as a first line test in place of postnatal karyotyping for genome imbalance. Mol Cytogenet 2010, 3:9.

10. Miller DT, Adam MP, Aradhya S, Biesecker LG, Brothman AR, Carter NP, Church DM, Crolla JA, Eichler EE, Epstein CJ, et al: Consensus statement: chromosomal microarray is a first-tier clinical diagnostic test for individuals with developmental disabilities or congenital anomalies. Am J Hum Genet 2010, 86:749-764.

11. Manning M, Hudgins L: Array-based technology and recommendations for utilization in medical genetics practice for detection of chromosomal abnormalities. Genet Med 2010, 12:742-745.

12. Choe J, Kang JK, Bae CJ, Lee DS, Hwang D, Kim KC, Park WY, Lee JH, Seo JS. Identification of origin of unknown derivative chromosomes by arraybased comparative genomic hybridization using pre- and postnatal clinical samples. J Hum Genet 2007, 52:934-942.

13. Kim JI, Ju YS, Park H, Kim S, Lee S, Yi JH, Mudge J, Miller NA, Hong D, Bell $C J$, et al: A highly annotated whole-genome sequence of a Korean individual. Nature 2009, 460:1011-1015.

14. Park H, Kim Jl, Ju YS, Gokcumen O, Mills RE, Kim S, Lee S, Suh D, Hong D, Kang HP, et al: Discovery of common Asian copy number variants using integrated high-resolution array CGH and massively parallel DNA sequencing. Nat Genet 2010, 42:400-405.

15. Cheung SW, Shaw CA, Yu W, Li J, Ou Z, Patel A, Yatsenko SA, Cooper ML, Furman P, Stankiewicz P, et al: Development and validation of a CGH microarray for clinical cytogenetic diagnosis. Genet Med 2005, 7:422-432

16. Shaffer LG, Bejjani BA, Torchia B, Kirkpatrick S, Coppinger J, Ballif BC: The identification of microdeletion syndromes and other chromosome abnormalities: cytogenetic methods of the past, new technologies for the future. Am J Med Genet C Semin Med Genet 2007, 145C:335-345.

17. Shaffer LG, Coppinger J, Alliman S, Torchia BA, Theisen A, Ballif BC, Bejjani BA: Comparison of microarray-based detection rates for cytogenetic abnormalities in prenatal and neonatal specimens. Prenat Diagn 2008, 28:789-795.

18. Otto EA, Helou J, Allen SJ, OToole JF, Wise EL, Ashraf S, Attanasio M, Zhou W, Wolf MT, Hildebrandt F: Mutation analysis in nephronophthisis using a combined approach of homozygosity mapping, CEL I endonuclease cleavage, and direct sequencing. Hum Mutat 2008, 29:418-426.

19. Slavotinek AM: Novel microdeletion syndromes detected by chromosome microarrays. Hum Genet 2008, 124:1-17.
20. Mencarelli MA, Katzaki E, Papa FT, Sampieri K, Caselli R, Uliana V Pollazzon M, Canitano R, Mostardini R, Grosso S, et al: Private inherited microdeletion/microduplications: implications in clinical practice. Eur J Med Genet 2008, 51:409-416.

21. Edelmann L, Hirschhorn K: Clinical utility of array CGH for the detection of chromosomal imbalances associated with mental retardation and multiple congenital anomalies. Ann N Y Acad Sci 2009, 1151:157-166.

22. Shaffer $L G$, Beaudet $A L$, Brothman AR, Hirsch B, Levy B, Martin $C L$, Mascarello JT, Rao KW, et al: Microarray analysis for constitutional cytogenetic abnormalities. Genet Med 2007, 9:654-662.

23. Shaffer LG: American College of Medical Genetics guideline on the cytogenetic evaluation of the individual with developmental delay or mental retardation. Genet Med 2005, 7:650-654.

24. Darilek S, Ward P, Pursley A, Plunkett K, Furman P, Magoulas P, Patel A, Cheung SW, Eng CM: Pre- and postnatal genetic testing by arraycomparative genomic hybridization: genetic counseling perspectives. Genet Med 2008, 10:13-18.

25. Sahoo T, Cheung SW, Ward P, Darilek S, Patel A, del Gaudio D, Kang SH, Lalani SR, Li J, McAdoo S, et al: Prenatal diagnosis of chromosomal abnormalities using array-based comparative genomic hybridization. Genet Med 2006, 8:719-727.

26. Sudha T, Dawson AJ, Prasad AN, Konkin D, de Groot GW, Prasad C: De novo interstitial long arm deletion of chromosome 3 with facial dysmorphism, Dandy-Walker variant malformation and hydrocephalus. Clin Dysmorphol 2001, 10:193-196.

27. Grinberg I, Northrup H, Ardinger H, Prasad C, Dobyns WB, Millen KJ: Heterozygous deletion of the linked genes $\mathrm{ZIC1}$ and $\mathrm{ZIC} 4$ is involved in Dandy-Walker malformation. Nat Genet 2004, 36:1053-1055.

28. Kurotaki N, Stankiewicz P, Wakui K, Niikawa N, Lupski JR: Sotos syndrome common deletion is mediated by directly oriented subunits within inverted Sos-REP low-copy repeats. Hum Mol Genet 2005, 14:535-542.

29. Van Esch H, Hollanders K, Badisco L, Melotte C, Van Hummelen P, Vermeesch JR, Devriendt K, Fryns JP, Marynen P, Froyen G: Deletion of VCX-A due to NAHR plays a major role in the occurrence of mental retardation in patients with X-linked ichthyosis. Hum Mol Genet 2005, 14:1795-1803

30. Lonardo F, Parenti G, Luquetti DV, Annunziata I, Della Monica M, Perone L, De Gregori M, Zuffardi O, Brunetti-Pierri N, Andria G, Scarano G: Contiguous gene syndrome due to an interstitial deletion in Xp22.3 in a boy with ichthyosis, chondrodysplasia punctata, mental retardation and ADHD. Eur J Med Genet 2007, 50:301-308.

31. Ouldim K, Natiq A, Jonveaux P, Sefiani A: Tetrasomy 15q11-q13 Diagnosed by FISH in a Patient with Autistic Disorder. J Biomed Biotechnol 2007, 2007:61538.

32. Crolla JA, Youings SA, Ennis $S$, Jacobs PA: Supernumerary marker chromosomes in man: parental origin, mosaicism and maternal age revisited. Eur J Hum Genet 2005, 13:154-160.

33. Kurahashi H, Shaikh TH, Hu P, Roe BA, Emanuel BS, Budarf ML: Regions of genomic instability on $22 \mathrm{q} 11$ and $11 \mathrm{q} 23$ as the etiology for the recurrent constitutional t(11;22). Hum Mol Genet 2000, 9:1665-1670.

34. Rudd MK, Keene J, Bunke B, Kaminsky EB, Adam MP, Mulle JG, Ledbetter DH, Martin CL: Segmental duplications mediate novel, clinically relevant chromosome rearrangements. Hum Mol Genet 2009, 18:2957-2962

doi:10.1186/1755-8166-4-12

Cite this article as: Park et al: Clinical implementation of whole-genome array CGH as a first-tier test in $\mathbf{5 0 8 0}$ pre and postnatal cases. Molecular Cytogenetics 2011 4:12. 